\title{
Aportes de la geografía humanística para la comprensión de los lugares de miedo al delito en la ciudad ${ }^{1}$
}

\author{
Contributions of Humanistic Geography for Understanding the \\ Places of Fear of Delinquency in the City
}

Jaime Alberto Barinas Salcedo ${ }^{2}$

Para citar este artículo, utilice el nombre completo así:

Barinas Salcedo, J. A. (2014). Aportes de la geografía humanística para la comprensión de los lugares de miedo al delito en la ciudad. Perspectiva Geográfica, 19(2), 241-258

\section{Resumen}

El miedo al delito hace parte de las inseguridades del mundo en la actualidad; dichas incertidumbres se afianzan y expresan en la experiencia diaria de los individuos y el intercambio perceptivo con el espacio. La finalidad de este artículo es realizar una aproximación desde la geografía humanística a la interpretación socioespacial de los lugares de miedo al delito en la ciudad, a partir de la comprensión de los imaginarios y experiencias de los sujetos y la forma como estos influyen en las relaciones propias dentro del espacio urbano.

Palabras clave: construcción social, experiencia espacial, imaginario urbano, lugar de miedo.

\section{Abstract}

Fear of delinquency is part of the insecurities of the world today. Those insecurities are both fixed and expressed in the daily experience of individuals and the perceptive interchange with their surrounding space. The goal of this article is to carry out an approach from the perspective of humanistic geography

1 Lugares de miedo (topofobias): experiencias e imaginarios del miedo al delito en el espacio urbano de la localidad de Chapinero.

2 Magíster en Geografía, Universidad Pedagógica y Tecnológica de Colombia en convenio con el Instituto Geográfico Agustín Codazzi. Docente jefe de área, Colegio Emmanuel d’Alzon. jabarinas@hotmail.com; barinasjaime@gmail.com 
to the socio-spatial construct of fear-to-delinquency places in the city, starting from the understanding of imaginaries and experiences of individuals and the way these influence their own relationships within the urban space.

Keywords: social construct, spatial experience, urban imaginary, fear-todelinquency place. 


\section{Introducción}

A mediados del siglo XIX la geografía se consolida como ciencia cuyo objeto de estudio se centra en la diferenciación de la superficie terrestre. En este sentido, se privilegiaron estudios de tipo lógico-positivista propios de la geografía regional, que predominaron hasta mediados de la década del sesenta del siglo XX. En la década siguiente surge el enfoque humanístico como crítica al dominio positivista, y permite el estudio del espacio como lugar de vida del hombre.

La geografía humanística, apoyada en los enunciados de la fenomenología y el existencialismo, ha potenciado el estudio de la relación del ser humano y el espacio en toda su amplitud y detalle, privilegiando la existencia humana como elemento fundamental, ya que apropia, experimenta y significa el espacio, abriendo la posibilidad de realizar otro tipo de estudios distintos a los que se habían hecho hasta el momento.

El enfoque geográfico humanístico articula y resignifica el concepto de lugar, entendiéndolo como centro de significados y asentamiento de la experiencia de los individuos. Dicho concepto ha permitido el uso de métodos y técnicas cualitativas en tanto se pretende comprender las relaciones, representaciones $\mathrm{y}$ prácticas del hombre en el espacio.
En ese orden de ideas, la geografía humanística y el lugar permiten abordar diversidad de temas, entre ellos la comprensión de las relaciones de los sujetos con los lugares de miedo asociados a los delitos en la ciudad; tema de suma importancia ya que los lugares de miedo influyen en las relaciones y formas de apropiar y vivir el espacio urbano.

Sin embargo, para comprender las experiencias, relaciones e imaginarios de los lugares de miedo y como ello se expresa en el espacio urbano, es necesario tener claro que dichos lugares son construcciones sociales, ya que son los individuos con sus sentidos y pensamientos quienes cargan de significado los espacios que habitan y frecuentan cotidianamente.

Así mismo, un lugar de miedo es una experiencia espacial, puesto que los sujetos vinculan sus sentidos, la información y la subjetividad con el espacio que les genera temor, creando un imaginario urbano individual o colectivo, que es capaz de influir en las prácticas sociales y las formas que adopta la ciudad para evitar el miedo al delito.

Es preciso afirmar que el lugar de miedo como imaginario urbano se hace evidente en la forma como el sujeto se relaciona con la ciudad para mitigar dicha sensación de pánico; es por ello que sus desplazamientos, los 
conjuntos cerrados, la construcción de muros, el uso de alarmas, la vigilancia privada, entre otros, constituyen acciones y prácticas sociales encaminadas a dicho fin.

Sin embargo, es válido afirmar que dichas prácticas reducen el espacio de vida de los habitantes de la ciudad, al tiempo que los encierra, lo cual interfiere su relación con el espacio urbano y los demás individuos. En ese orden de ideas, la ciudad se convierte en un espacio producido y reproducido por los miedos (Merino \& Sánchez, 2007).

\section{Fundamentos de la geografía humanística}

La geografía humanística es un enfoque que surge en Estados Unidos en la década de los setenta como crítica o alternativa al enfoque lógico-positivista, ya que este utilizaba modelos exactos, objetivos y mecanicistas que relegaban al ser humano y su carga de sentimientos, identidad y significados asociados al espacio.

El enfoque lógico-positivista dominó desde que la geografía se consolida como ciencia en el siglo XIX. Tal como lo señala Ballesteros (1998), esta se centraba en dar explicación a los procesos de urbanización, industrialización, migración, expansionismo, entre otros. En dichos análisis lo fundamental era dar cuenta de la fisionomía del paisaje, por lo tanto se acudía a la geografía física cuyo objetivo era la diferenciación de la superficie terrestre.

Por tal motivo, como lo afirma Delgado (2003), por mucho tiempo la geografía estuvo dominada por el pensamiento de Durkheim seguidor de la metodología positivista de Comte- excluyendo de esta ciencia asuntos de la conciencia y la motivación del hombre; escasamente se interpretó la acción del sujeto en los análisis de tipo de vivienda, sistemas agrarios y las formas de asentamiento.

Es por ello que el enfoque humanístico en la geografía es una crítica directa contra la sociedad tecnológica y contra el monopolio de la ciencia positivista que limitaba al hombre, dejando de lado aspectos importantes como los sentimientos, pensamientos, instituciones etc. Por lo tanto, el humanismo en la geografía lucha contra las limitaciones del positivismo lógico sin ser excluyente, ya que no niega que el hombre pueda estudiarse desde una perspectiva científica incluyendo otros métodos que revelan la preocupación humana.

Al respecto, como señala Estebánez (1984), este enfoque propone hacer una geografía humana con hombres, una geografía antropocéntrica apoyada en el existencialismo y la fenomenología. 
Es decir, una geografía humanizada que estudia la tierra como hogar del hombre, más pendiente del lugar, las comunidades y el entorno.

La fenomenología, por su parte, se basa en el pensamiento de Edmun Huserl y pretende una mirada integral de los fenómenos. Como lo afirma Delgado (2003), una mirada que no separa las apariencias de las esencias, que destaca las vivencias y le da importancia a la subjetividad. Por ende, este método requiere que las cosas se describan como se experimentan cotidianamente, ya que la fenomenología reivindica la experiencia cotidiana de las personas como algo esencial en la comprensión de los seres humanos en el mundo (Delgado, 2003).

Ahora bien, el existencialismo, como filosofía del sujeto, intenta abarcar todo su rango de existencia en el aquí y en el ahora. Al respecto, Sartre, citado por Delgado (2003, p.103), indica que "la existencia es anterior a la esencia y es en la existencia donde se define el sujeto". Por lo tanto, para los existencialistas el mundo no existe aparte de los hombres, ya que en él viven, y dada la diversidad de intereses, se puede afirmar que existen múltiples mundos cuya manera de comprenderlos no es acudiendo a la objetividad y racionalidad científica.

La geografía humanística articula su enfoque holístico en torno al con- cepto de lugar, entendido este como centro de significados, condición de la propia experiencia, contexto para nuestras acciones y fuente de la identidad. Este concepto de lugar se opone al geometrizado espacio abstracto del positivismo, pues está lleno de interpretaciones y valores inseparables de la experiencia de quienes lo habitan.

A partir del concepto mencionado anteriormente es posible darle al estudio del paisaje unas dimensiones simbólicas y culturales, concebirlo como un paisaje experiencial-holístico. En efecto, Ballesteros (1998) afirma que la incidencia del lugar en el estudio del paisaje es abordado en función de las experiencias asociadas con el mismo, los individuos y grupos que lo habitan.

Es de vital importancia manifestar que la geografía humanística en su afán de estudiar el lugar ha potenciado métodos y técnicas de análisis enmarcadas en el conjunto de los métodos cualitativos utilizados para entender las relaciones, representaciones y prácticas del hombre en el espacio. Ballesteros (1998) expone que además de la memoria histórica, se acude a la observación participante weberiana para comprender lo subjetivo de los lugares, proponiendo los recursos del trabajo de campo, los aportes de la literatura, la pintura y elaboración de cartografías de la realidad (ver Figura 1). 


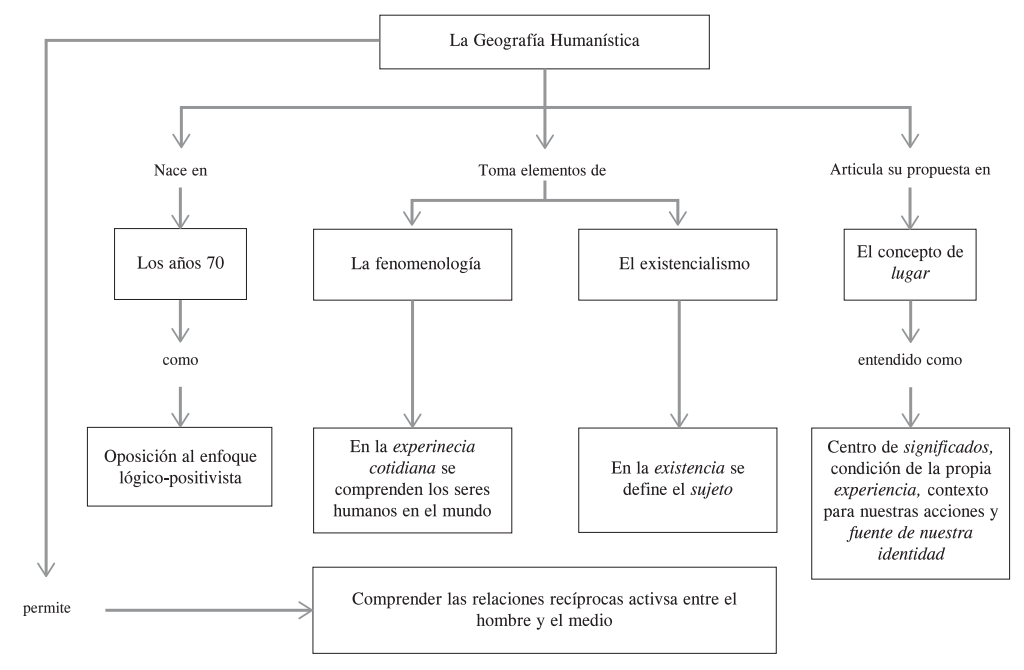

Figura 1. Definición de geografía humanística

Fuente: elaboración propia.

En último término, es válido afirmar que la geografía humanística ha potenciado una dimensión más cultural en la disciplina geográfica, reformulando conceptos, empleando recursos y técnicas de investigación que suponen un mayor contacto con los lugares y la vida cotidiana. Por lo tanto, su carácter holístico la ha llevado a interpretar las relaciones recíprocas activas entre el hombre y el medio.

\section{El lugar como construcción social}

El lugar es un concepto de mucha relevancia en la sociedad contemporánea y puede definirse desde enfoques y concepciones teóricas que lo transforman constantemente. Sobre este concepto se han hecho múltiples interpretaciones; por una parte, se concibe como un punto fijo en el espacio con una localización concreta y una distancia que son medibles y cuantificables; por otra parte, se afirma que el lugar no es solo una localización, también tiene identidad, valores y rasgos que lo hacen particular.

Dicha discusión, como se afirmó anteriormente, se da entre dos enfoques geográficos distintos que tienen una definición particular del lugar. Para los enfoques relacionados con la geografía física, entre los que se destaca la geografía regional, que predominó hasta mediados del siglo $\mathrm{XX}$, tanto el lugar como el espacio geográfico son conceptos susceptibles de medir, cuantificar, predecir y explicar (Matthews \& Herbert, 2008); por el 
contrario, para el enfoque geográfico humanístico, que nace en la década del setenta, el lugar es entendido como centro de significados, condición de la experiencia, contexto de las acciones y fuente de identidad para los individuos (Ballesteros, 1998).

En este último enfoque se plantea hacer una geografía distinta a lo propuesto hasta la década del sesenta, que consiste, en palabras de Estébanez (1984), en realizar una geografía cercana al sujeto, basada en los aportes del existencialismo y la fenomenología; de allí que se entienda el lugar como escenario insustituible de las pasiones humanas, responsables, a través de las acciones comunicativas, de diversas manifestaciones de espontaneidad y creatividad (Santos, 2000).

El lugar, desde la geografía humanística, es entonces un concepto fundamental donde confluyen las experiencias de vida y los significados que hacen parte de la esencia y la existencia humana; de esta forma, el sujeto, sus sentidos y pensamientos conocen y construyen la realidad simbolizando y cargando de emociones los espacios que habita y frecuenta cotidianamente (Delgado, 2003).

Se afirma que en la construcción social del lugar se vincula la experiencia del sujeto (sus acciones y lo tangible) con lo subjetivo (pensamientos e imaginarios), que se da en las relaciones cotidianas con el espacio.

$\mathrm{Al}$ respecto, Zapata (2008) considera que el espacio apropiado se instala en lo urbano, como lugar concebido bajo la idea de construcción social y cultural, cargado con un sistema de representaciones sobre sí, lo que permite la aprehensión conceptual del espacio que se relaciona con las vivencias del sujeto, estableciendo sus usos y sus magnitudes tanto afectivas como físicas (ver Figura 2).

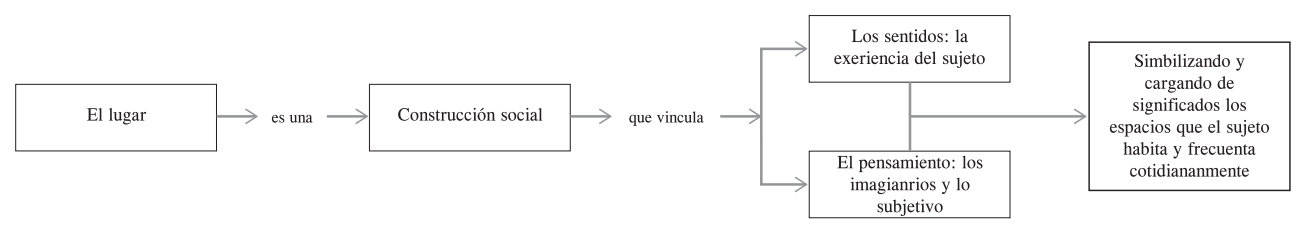

Figura 2. Lugar como construcción social

Fuente: elaboración propia.

\subsection{El lugar como experiencia espacial}

El lugar representa la forma del ser humano en el espacio; por tanto, habitar el lugar es ser en el mundo (Uribe, 2011). Lo que significa darle sentido en un proceso de interpretación y construcción de espacios de 
vida producidos por el ser humano, que los carga de valores al tiempo que desarrolla sus prácticas cotidianas. Es allí donde la experiencia del espacio involucra todos los sentidos, la visión, el gusto, el oído, el olfato y la sensibilidad de la piel, que, combinados, enriquecen la aprehensión del carácter espacial del mundo (Delgado, 2003).

En este sentido, la experiencia espacial es un concepto integrador que vincula tanto las prácticas como la información y la subjetividad espacial; por ende, la reflexión sobre la experiencia y la vivencia como parte fundamental del sujeto, son esenciales para la comprensión del lugar de los seres humanos en el mundo (Delgado, 2003).

En efecto, como lo afirma Tuan (2007), es imposible hablar de la experiencia del espacio sin tener en cuenta los objetos y lugares que lo definen (ver Figura 3). El espacio abstracto se vuelve concreto en el lugar y se llena con significados. Su conocimiento se logra más por la experiencia que por la simple instrucción formal: para aprender sobre el espacio y el lugar es necesario vivirlos plenamente (Delgado, 2003).

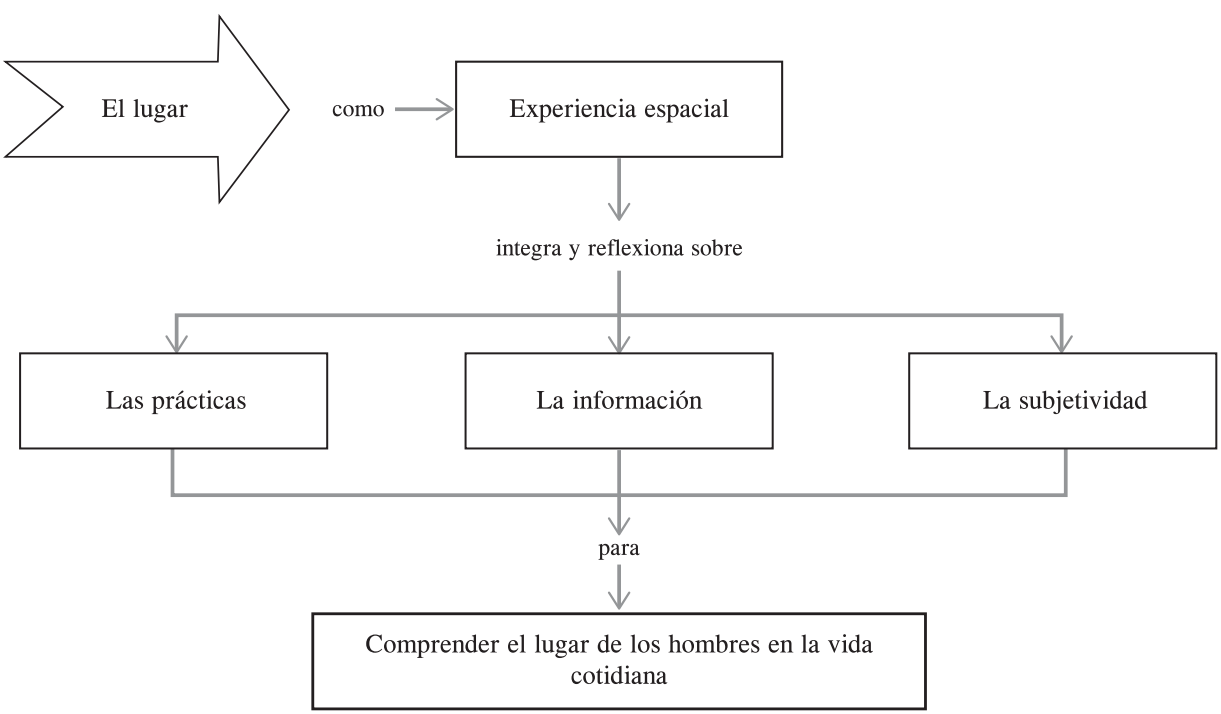

Figura 3. Lugar como experiencia espacial

Fuente: elaboración propia.

Al respecto, Lindón (2007) afirma que el lugar puede explicarse como una dialéctica entre el espacio y la sociedad; esto quiere decir que el lugar es concebido como productor de lo social y al mismo tiempo como 
producto social, es por ello que los sujetos construyen el lugar y el lugar es construido socialmente moldeando la vida que allí se aloja.

Puede entonces afirmarse que la experiencia espacial permite la comprensión de la relación espaciohombre-pensamiento desde una mirada holística. El hombre y el espacio se relacionan desde lo corporal con el sentir, percibir y concebir los elementos materiales del entorno (Lindón, 2007). Así mismo, la relación entre el pensamiento y lo espacial se entiende desde las relaciones simbólicas y los imaginarios que se construyen en el lugar a partir de las acciones diarias. El lugar como construcción social y experiencia espacial conecta lo material con lo simbólico que necesariamente está anclado en lo espacial durante el transcurrir de las prácticas sociales cotidianas.

\subsection{Lugar como imaginario urbano}

El lugar como experiencia espacial está cargado de vivencias, sentimientos y significados; la apropiación de este se hace a través de los imaginarios urbanos que se construyen a partir de la relación entre las personas y el espacio; dicha apropiación, como lo afirman Lindón, Hiernaux y Aguilar (2006), es lo que construye socialmente el espacio en "múltiples lugares".
Para hablar del concepto de imaginarios urbanos es necesario subrayar dos pilares, como son "la subjetividad y la elaboración simbólica", por lo tanto, el valor analítico de los imaginarios es la posibilidad de reconstruir visiones del mundo, desde las cuales los sujetos tienen un propósito y construyen su realidad (Lindón et al., 2006).

Por ende, las imágenes, las imaginaciones, los modos de representación de la vida en las ciudades, como: la seguridad, la acción pública, la proximidad, las estrategias residenciales, las nociones sobre los otros habitantes, se inscriben en la sociedad desde las formas particulares de combinar información, experiencias, carencias y fantasías, que se resisten a ser entendidas desde criterios meramente objetivos, objetivistas o racionalistas (Lindón, 2006a).

En este sentido, las representaciones e imágenes son construidas tanto por los sujetos de manera autónoma, como desde las relaciones sociales, por ejemplo, el hecho de habitar la ciudad que obliga a los individuos a compartir un repertorio común de elementos simbólicos que, como afirman Niño, Lugo, Rozo y Vega (1998), son referentes espaciales cargados de valor para conformar imágenes y representaciones mentales del espacio que se habita. De esta forma, el mundo del imaginario 
tiene un efecto social concreto, tanto individual como colectivo, en el comportamiento de los ciudadanos y en la forma que toman las relaciones e interacciones que están dispuestos a establecer (ver Figura 4).

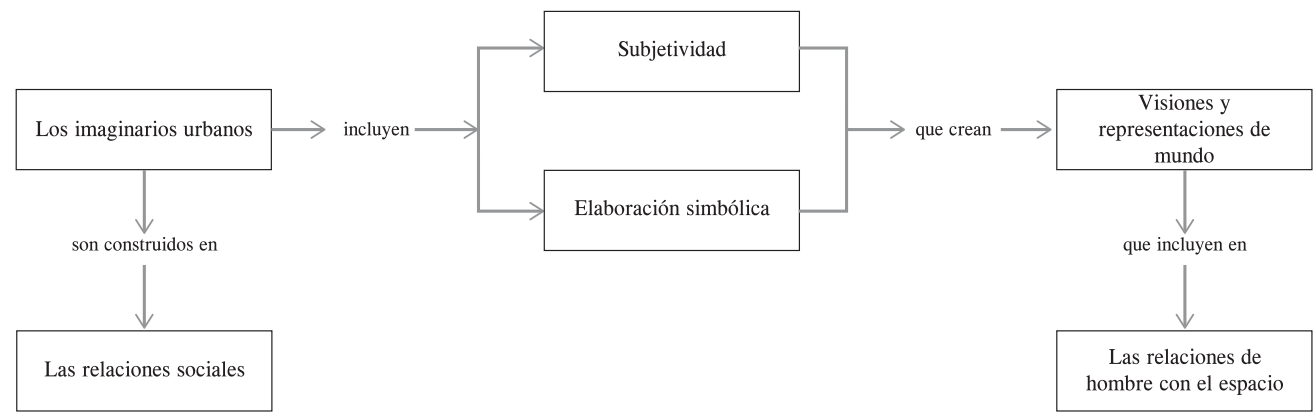

Figura 4. Lugar como imaginario urbano

Fuente: elaboración propia.

Tener una determinada imagen de la ciudad facilita o dificulta la relación con el espacio, toda vez que la misma sea determinante a la hora de seleccionar espacios, tiempos y personas con las que el individuo quiere o no tener un encuentro; dicha imagen que porta el sujeto es construida socialmente y como lo afirman Niño et al., (1998), buscará correspondencia en el mundo de las percepciones generando todo un conjunto de sensaciones y emociones en la relación cotidiana con el espacio.

Son múltiples los imaginarios que se construyen socialmente en la relación de los sujetos con el espacio que habitan y en el cual se desarrollan cotidianamente; uno de los imaginarios más comunes es el relativo a la construcción social del miedo al delito, que, según Lindón (2006a), se desenvuelve en un proceso de creación de figuras y lugares amenazantes que disgregan la experiencia de la ciudad al someterla al principio de amenaza.

Se trata del miedo que habita en el imaginario y que es capaz de provocar sensaciones a partir de experiencias e imágenes relacionadas con espacios, sujetos, momentos o actividades que pueden ser asociadas de alguna manera con situaciones generadoras del pánico (Niño et al., 1998). Son entonces imaginarios relacionados con la inseguridad, el riesgo, el peligro y el abuso, que provocan el miedo modificando la forma en que los sujetos se relacionan con ciertos espacios en la ciudad.

Según Martel y Baries (2006), es necesario tener en cuenta que la imagen de lo inseguro se deriva de tres fuentes 
principales: experiencias personales, relatos de otras personas y relatos difundidos desde los medios de comunicación. Por lo tanto, se puede afirmar que los imaginarios del miedo al delito hacen parte de una construcción personal y colectiva que se fundamenta en la vivencia cotidiana construyendo las formas de habitar, apropiar, nombrar y estigmatizar ciertos espacios con la inseguridad y el riesgo.

\section{El lugar de miedo al delito}

Es importante aclarar que un lugar de miedo al delito es un imaginario urbano que se construye socialmente en las relaciones cotidianas de los habitantes de la ciudad, a partir de experiencias directas o por noticias y comentarios relacionados con hechos delictivos sucedidos en ciertos espacios de esta. Dicho lugar produce sensaciones topofóbicas o de rechazo, que suelen asociarse a ciertas características físicas como la oscuridad, la soledad, la suciedad, el mal olor, la infraestructura en mal estado o incluso la presencia de ciertos actores.

Los lugares de miedo tienen un efecto social concreto, dada su influencia en el comportamiento de los ciudadanos, ya que modifica la forma como los sujetos se relacionan con la ciudad, puesto que delimita las relaciones que se dan en determinados sectores de la misma (Segura, 2009).
Dichos lugares generan desplazamientos de unos y permanencias de otros, así como nuevas vivencialidades y nuevas percepciones socioculturales del lugar, que se hacen evidentes en la construcción de conjuntos cerrados, la edificación de muros, el uso de alarmas, la seguridad privada, entre otros (Zapata, 2008).

Señaladas las anteriores disertaciones, puede añadirse, tal como lo afirma Gutiérrez (2005), que el miedo al delito se traduce en acciones y prácticas sociales, en donde el sujeto crea rupturas con las relaciones de su medio, sean estas humanas o con su espacio de vida; es por ello que el miedo no solo actúa dificultando las interacciones humanas sino que reduce el espacio de vida, encierra al individuo, disminuye la percepción y la sensibilidad, que son factores vitales de la relación con el espacio (Gutiérrez, 2005).

Es indispensable indicar que los lugares de miedo son construcciones sociales (ver Figura 5), a partir de la experiencia espacial en la dialéctica hombre-ciudad, que se traducen en imaginarios urbanos que influyen en la manera como el sujeto se relaciona con el medio. De ahí que la urbe, como lo afirman Merino y Sánchez (2007), se convierta entonces en un espacio "producido y reproducido" por los miedos sociales. 


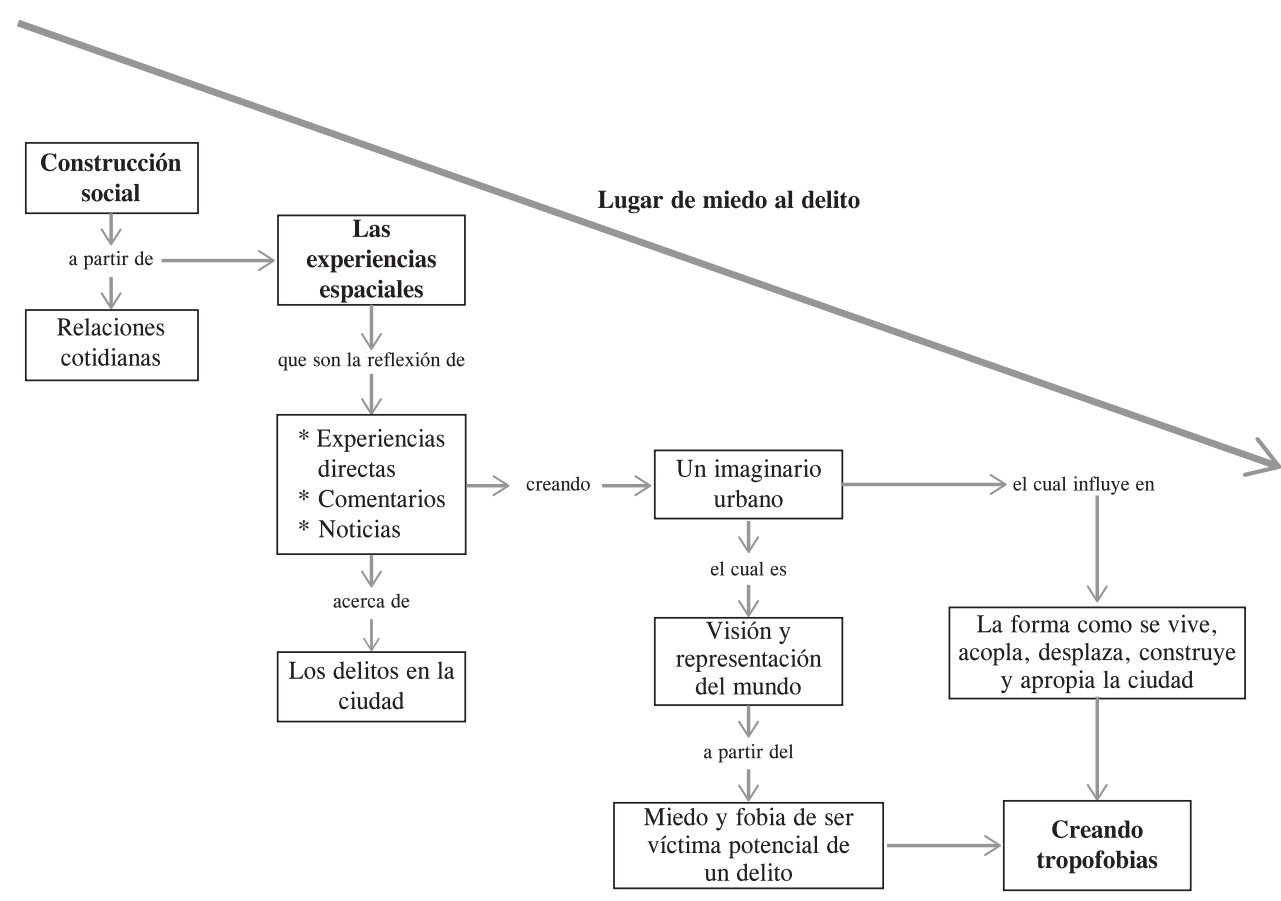

Figura 5. Concepto de lugar de miedo al delito

Fuente: elaboración propia.

3.1 Comprensión de los lugares de miedo al delito

Siendo la ciudad un espacio compuesto por múltiples lugares de miedo al delito, es indispensable comprender como estos se construyen e influyen en la forma en que los habitantes crean nuevas vivencialidades, nuevas percepciones y relaciones con el espacio urbano en las situaciones cotidianas. Este ejercicio implica estudiar y comprender su realidad socioespacial desde la experiencia y el imaginario de las personas; por tal motivo es necesario interpretar los significados y valores que cada individuo elabora a través de la interacción con los demás.

En este sentido es fundamental llegar a la comprensión e interpretación de estos lugares de miedo mediante el estudio a profundidad, indagando sobre las sensaciones y las experiencias directas e indirectas recibidas, que posteriormente cobran significado y complejidad, para luego regular la interacción de los individuos con el espacio en el cual residen (Pyszczek 2012), (ver Figura 6). 


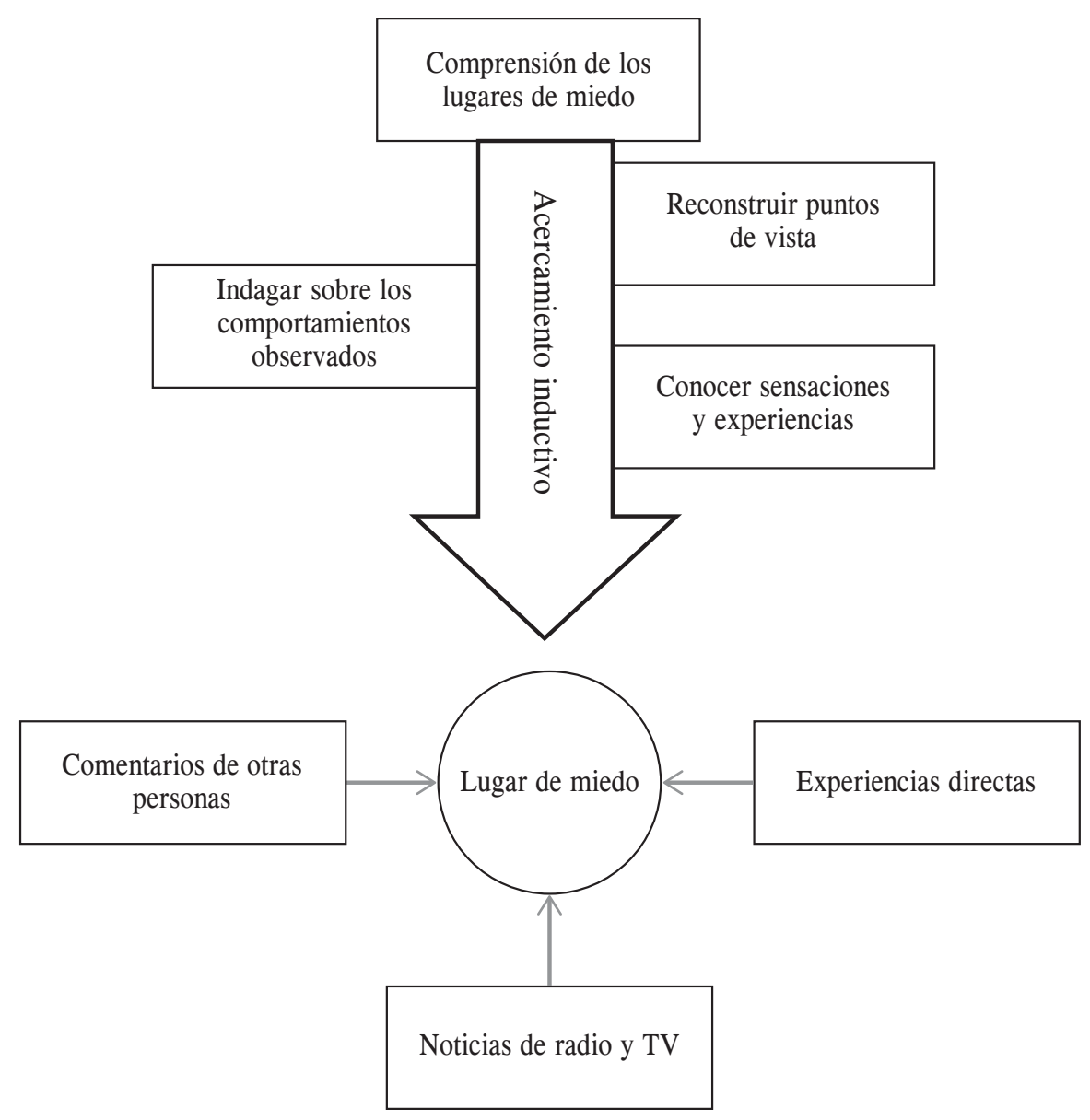

Figura 6. Comprensión de los lugares de miedo al delito

Fuente: elaboración propia.

Según lo mencionado anteriormente, de comunicación también influyen al también es preciso afirmar que es reportar sobre delitos (Cook, 2010). indispensable acercarse a las formas como surge el miedo al delito, que pueden darse por: 1 . La experiencia personal, en este caso la persona fue víctima de un delito o es muy cercana a una víctima de un delito. 2 . Reacción a los medios o a las influencias de otras personas, los medios

Por ello es importante indagar a través de las palabras habladas o escritas de las personas y sus comportamientos directamente observados, sobre las dos dimensiones -objetiva y subjetiva- que poseen los miedos al delito, puesto que esta interre 
lación constituye una experiencia socialmente construida que, incluso, como afirma Barata (2010), se refuerza con las imágenes impactantes, los relatos dramáticos y los titulares sensacionalistas.

Por tanto, para comprender e interpretar los lugares de miedo al delito es necesario partir de una experiencia anómala reconstruyendo los puntos de vista de los implicados en su contexto (Valles, 2003). Dicha experiencia está asociada con una relación incómoda que establece el sujeto con ese lugar, debido a un estado de pánico y fobia ligados a hechos delictivos.

De acuerdo con Lindón (2006a), la relación del pánico con el espacio es reconocida por el geógrafo humanístico YI Fu Tuan, como topofobia y "ésta tiene grados que van desde la sensación de incomodidad leve hasta el rechazo profundo por el lugar o incluso miedo y pánico que le impide al sujeto estar en cierto lugar" (Lindón, 2006a, p. 47).

Se plantea entonces interpretar en su contexto los lugares de miedo al delito o las topofobias al delito, reconstruyendo los diversos puntos de vista de los ciudadanos que han experimentado aquellas sensaciones persiguiendo una interpretación de la reacción de los individuos y la manera como se refleja y se expresa en sus lugares cotidianos (Lindón, 2006a).

De acuerdo con lo planteado hasta el momento es propicio reconstruir la experiencia vivida por los actores que han construido los lugares de miedo al delito para comprender los imaginarios que provocan sensaciones incómodas y que se relacionan con espacios, sujetos, momentos o actividades que pueden ser asociadas de alguna manera con situaciones generadoras del pánico (Niño et al., 1998).

Al reconstruir las relaciones entre el miedo al delito y la manera como este se ancla en ciertos lugares de la ciudad, es posible entender cómo surge el imaginario colectivo con relación a ciertos lugares de miedo que son socialmente aceptados y generalizados en determinados sitios. Cabe anotar que el miedo se manifiesta en el espacio convirtiendo en seguros aquellos con protección y vigilancia, e inseguros los que generan una situación de marginación.

Se concluye entonces que es una opción válida acercarse de forma inductiva a los lugares que producen miedo o sensaciones topofóbicas a partir de experiencias relacionadas con el delito, ya que permite al investigador indagar a los sujetos para comprender las percepciones y sensaciones, de forma que se pueda 
analizar como el miedo toma una dimensión espacial limitando dinámicas, desmovilizando o restringiendo actividades de trabajo, ocio y recreación en la vida cotidiana de las personas.

Por tal motivo, indagar acerca de los lugares de miedo es la posibilidad de comprender por qué el miedo al delito influye en las lógicas de la ciudad, ya que puede conducir a adoptar formas de desarrollo urbano y conductas de protección dentro y fuera de lo privado (Zapata, 2008).

\subsection{La ciudad como expresión del miedo al delito}

La ciudad como escenario de múltiples relaciones entre los individuos que la habitan y las conexiones que allí se desarrollan, se convierte en un espacio geográfico con variadas dimensiones de análisis; no solamente se estudia aquello que es medible, cuantificable y explicable, también aquellos símbolos y significados que los sujetos le dan a ciertos lugares que representan espacios de bienestar, sitios poco frecuentados o de miedo por circunstancias ligadas a hechos delictivos.

En este sentido es fundamental analizar los espacios urbanos estigmatizados por los delitos, para conocer las implicaciones espaciales que afectan los comportamientos de las personas que sufren los efectos de la violencia (Sáenz, 2008), ya que es claro que dichos espacios imposibilitan el encuentro en la calle, la plaza y la ciudad, puesto que el miedo al delito toma una dimensión espacial que limita dinámicas de trabajo, ocio y recreación en la vida cotidiana (Merino \& Sánchez, 2007).

Es por ello, como lo expresan Merino y Sánchez (2007), que el miedo al delito se traduce en acciones y prácticas sociales de los sujetos en la ciudad, que crean rupturas con el medio, dificultan las relaciones humanas, reducen los espacios de vida encerrando al individuo, disminuyendo su percepción y sensibilidad, los cuales son factores vitales en la relación con el espacio.

Al respecto es notable como los peligros y temores, así como su percepción y manipulación, aportan una clave privilegiada para comprender la ciudad en sus diferentes facetas, desde los comportamientos, la vida cotidiana y las expresiones culturales, hasta los proyectos urbanísticos, las formas de crecimiento, incluso en la composición interna del espacio urbano (Gutiérrez, 2005).

Es indispensable entonces reconocer la realidad ciudadana del espacio vivido en la experiencia propia y revelada por las imágenes mentales 
creadas por la inseguridad y el miedo (Gutiérrez, 2005); dichas imágenes se integran a los valores propios de la ciudad, como los espacios públicos (plazas, parques, calles, centros comerciales); de ahí la importancia de entender cómo se conforman las nuevas arquitecturas, sus dinámicas, sus características.

La pretensión de este escrito es entonces destacar la importancia de comprender los lugares de miedo que generan situaciones de desprotección y marginación socioespacial donde se manifiesta la inseguridad urbana, para así reconquistar el territorio de la ciudad y facilitar una gestión participativa del espacio urbano con fines de desarrollo humano y solidario (Merino \& Sánchez, 2007).

\section{Conclusiones}

La geografía humanística y su enfoque holístico en torno al concepto de lugar ha propiciado una dimensión cultural en la geografía, con el objeto de comprender de forma más cercana los lugares y la vida cotidiana del hombre dentro de la relación afectiva existencial del individuo y el espacio; de este modo abre la posibilidad de abordar innumerables estudios, como la comprensión de los lugares de miedo al delito, a partir de las experiencias e imaginarios de los ciudadanos en las relaciones cotidianas.
Entendiendo el lugar como condición de la experiencia, contexto de las acciones y fuente de identidad para los individuos, es posible comprenderlo e interpretarlo a partir de los significados y valores que cada individuo elabora a través de la interacción con el espacio de la ciudad; por ende, se posibilita la comprensión de la relación topofóbica que existe entre algunos individuos y ciertos espacios urbanos asociados con hechos delictivos.

Un lugar de miedo al delito es una construcción social a partir de la experiencia espacial en la dialéctica hombre-ciudad, que se traduce en imaginarios urbanos que influyen en la manera como el sujeto se relaciona con la ciudad; por eso abre la posibilidad de investigarla para comprender aún más las nuevas vivencialidades en la ciudad, traducida en la manera como se concibe el espacio, se apropia y se construye.

De la mano con la temática tratada en este artículo, es preciso afirmar que se hace necesario investigar $y$ acercarse a ciertos espacios de la ciudad asociados con el delito y la violencia, ya que el imaginario que se crea de dicho lugar influye de forma evidente en la manera como se dan las relaciones en el espacio expresado en las formas de la ciudad, las rejas, los muros, la vigilancia privada, los desplazamientos, como 
alternativa para evitar dichos lugares que generan sensaciones de miedo, encerrando al hombre y quitándole la oportunidad de interactuar en el espacio de la ciudad.

\section{Referencias}

Ballesteros, A. (1998). Métodos y técnicas cualitativas en geografía social. Barcelona España: Oikos Tau.

Barata, F. (2010). Alarmismos sociales y medios de comunicación. Bogotá: Camara de Comercio de Bogotá, Alcaldía Mayor de Bogotá y Centro de estudios y Análisis en Convivencia y Seguridad Ciudadana.

Cook, P. (2010). Alarmismos sociales y medios de comunicación. Perspectivas y enfoques sobre percepción ciudadana. Bogotá: Camara de comercio de Bogotá, Alcaldía Mayor de Bogotá y Centro de Estudios y Análisis en Convivencia y Seguridad ciudadana.

Delgado, O. (2003). Debates sobre el espacio en la geografía contemporánea. Bogotá: Unibiblos, Universidad Nacional de Colombia.

Estébanez, J. (1984). Tendencias y problemática actual de la geografía. Madrid: Cincel.

Gutiérrez, O. (2005). La ciudad y el miedo. En VI coloquio de geografía urbana, Universitat de Girona, Barcelona.

Lindón, A. (2006a). Del suburbio como paraiso a la espacialidad periferica del miedo. En lugares e imaginarios de la metrópolis. México D.C: Anthropos.

Lindón, A. (2007). El constructivismo geográfico y las aproximaciones cualitativas. México D.C. Revista de Geografía Norte Grande, 37, 5-21.

Lindón, A. Hiernaux, D. \& Aguilar, M. (2006). De la espacialidad, el lugar y los imaginarios urbanos: a modo de introducción. En Lugares e imaginarios de la metropolis. México D.C: Anthropos.

Martel, R \& Baires, S. (2006). Imaginarios del miedo y geografías de la inseguridad: construcción social y sombólica del espacio público en San Salvador. México D.C: Anthropos.

Matthews, J. \& Herbert, D. (2008). Geography: a very short introduction. New York: University Press.

Merino, S. \& Sánchez, M. (2007). Geografía social de la ciudad. Aproximaciones al problema del miedo. Provincia del Chubut (Argentina). Párrafos Geográficos, 1.

Niño, S., Lugo, N., Rozo, C. \& Vega, L. (1998). Territorios del miedo en Santafé de Bogotá. Bogotá: TM Editores, Alcaldía Mayor de Santafé de Bogotá.

Pyszczek, O. (2012). Los espacios subjetivos del miedo: construcción de la estigmatización espacial en relación con la inseguridad delictiva urbana. Cuadernos de Geografía, 21(1), 41-54. 
Sáenz, H. (2008). La geografía y violencia urbana. Madrid: Universidad Complutense de Madrid.

Santos, M. (2000). La naturaleza del espacio. Barcelona: Ariel Geográfica.

Segura, R. (2009). Paisajes de miedo en la ciudad: miedo y ciudadanía en el espacio urbano de la ciudad de la Plata. Buenos Aires. Cuaderno Urbano (8), 59-91.

Tuan, Y. F. (2007). Topofilia. Un estudio de las percepciones, actitudes y valores sobre el entorno. España: Melusina.

Uribe, C. (2011). El lugar entre candados, rejas y miedos. Cali: Universidad del Valle Colombia.

Valles, M. (2003). Técnicas cualitativas de investigación social, reflexión metodología y práctica profesional. Madrid, España: Síntesis Sociológica.

Zapata, N. (2008). Territorialización del delito: aproximación conceptual para el abordaje del fenómeno en la ciudad. Bogota D.C. Estudios criminológicos, 335-347. 